\title{
Spectral Contrasts of Short Wind Waves in Artificial Slicks from the Sea Surface Photographs
}

\author{
V. A. Dulov, M. V. Yurovskaya \\ Marine Hydrophysical Institute of RAS, Sevastopol, Russian Federation \\ 凶mvkosnik@gmail.com
}

Purpose. The aim of the work is to evaluate the contrasts between the two-dimensional spectra of the short wind waves on a clean sea surface and on the surface covered by a thin film of vegetable oil. The contrast angular dependence, which is still not understood, is of particular interest. The study is intended to widen the base of empirical notions of wave suppression on the surfactant films in field conditions. Its results may be useful both for theoretical modeling the short wind wave spectra, and for developing the methods for remote monitoring of the ocean.

Method and Results. The contrasts were assessed by analyzing the sea surface photographs taken from the Platform of the Black Sea hydrophisical subsatellite polygon (Katsiveli) during the specialized experiments aimed at obtaining artificial slicks using vegetable oil spills. The applied in the study simple method for estimating the contrasts is based on the assumptions of a linear relationship between the brightness and the sea surface slope, and of the invariability of the brightness - slope transfer function at transition from a clean sea surface to a slick. In contrast to the previously applied methods, this approach makes it possible to obtain the contrasts varying both in wavenumber and direction. Obtaining the estimates of the shortest wave characteristics usually constitutes the utmost technical difficulty. In the work, the spectral contrasts are evaluated for the wind waves whose lengths are from $\sim 20$ to $\sim 1 \mathrm{~cm}$.

Conclusions. At moderate wind speeds $(6-8 \mathrm{~m} / \mathrm{s})$, the obtained contrasts increase monotonically with the wavenumber up to the values $\sim 10$. Under calm conditions (wind speed $0.5 \mathrm{~m} / \mathrm{s}$ ), the spectral contrast maximum ( 30-50) is observed at the wavenumber peak $~ 100 \mathrm{rad} / \mathrm{m}$ that is qualitatively confirmed by the estimates from a string wave gauge. These results are consistent with the previous measurements performed by the other authors. The two-dimensional contrast distributions are anisotropic with the maximum in the direction perpendicular to the wind one. At moderate winds, the anisotropy increases with growth of a wavenumber.

Keywords: sea surface slicks, short wind waves, wave spectrum, field measurements

Acknowledgements: the study was carried out within the framework of the state task on theme No. 0555-2021-0005 and at support of the RFBR grant No. 19-05-00-752A.

For citation: Dulov, V.A. and Yurovskaya, M.V., 2021. Spectral Contrasts of Short Wind Waves in Artificial Slicks from the Sea Surface Photographs. Physical Oceanography, [e-journal] 28(3), pp. 348-360. doi:10.22449/1573-160X-2021-3-348-360

DOI: $10.22449 / 1573-160 X-2021-3-348-360$

(C) V. A. Dulov, M. V. Yurovskaya, 2021

(C) Physical Oceanography, 2021

\section{Introduction}

Films on the sea surface remain a phenomenon intensively studied in marine hydrophysics, marine biology and ecology [1-5]. The study of surface-active substances (SAS) films of anthropogenic origin as a marine pollution indicator is necessary for the development and improvement of satellite monitoring systems for unauthorized oil spills, especially the consequences of accidents on oil platforms and ships [6-9]. Natural films of biological origin are interesting as indicators of bioproductivity and eutrophication zones [2, 10]. The sea surface smoothing (slicks) generated by them visualizes the features of currents, internal waves and convergence zones [1, 11-13]. 
SAS films change the surface tension of water and the elasticity of the sea surface; therefore, they can be used as a tool for studying phenomena at the water air interface. Since the thermodynamic properties of films of such substances as, for example, fish oil, vegetable oil, oleic acid, have been studied in laboratory conditions, they are used to create artificial slicks in the sea and wave tanks in order to set up targeted experiments for studying the process of film spreading, mechanisms of formation of short waves and wave breaking, the effect of the sea surface roughness on the air flow, etc. [1, 5, 14-17].

Spectral contrasts $K(\mathbf{k})$ - the ratio of the short waves' spectra in the absence of a film and in a slick, depending on the wave vectork, carry important information in these experiments. A simple theoretical model relating to the damping of short waves caused by the film was proposed in [1, 18 and 19]. Field measurements of spectral contrasts using an optical scatterometer are described in $[18,19]$. Radar measurements of spectral contrasts on artificial slicks in the sea, created using various SASs, were carried out from aircraft [20], satellites [4, 2123], vessels and platforms [1, 4, 24 and 25]. As a result of experimental and theoretical studies, a characteristic form of the spectral contrast dependence on the wave number was established [1, 24 and 25], while their dependence on azimuth relative to the wind direction remains not entirely clear. Knowledge of the azimuthal dependence is especially important for the interpretation of radar images of films [4, 22, 23 and 25].

The present paper continues field studies of spectral contrasts on artificial slicks. Contrasts were evaluated based on the processing of sea surface photographs. This method, in relation to those listed earlier, has the advantage that it permits to obtain a two-dimensional picture of contrasts immediately, i.e. their dependence on both the wavenumber and azimuth.

\section{Spectral Contrast Assessment Method}

According to numerous studies [14, 26-29], the assumption of a linear relationship between the radiance and the surface slope is fulfilled for the sea surface. Therefore, the spectrum of sea surface elevations $S_{H}$ can be obtained by multiplying the brightness spectrum of the $S_{B}$ photograph by the modulation transfer function (MTF) [28-32]:

$$
S_{H}=S_{B} \frac{1}{\left(G_{x} k_{x}+G_{y} k_{y}\right)^{2}},
$$

where $G_{x}, G_{y}$ are constants that require calibration of the method to obtain. Such a calibration, for example, in [28, 29, 32] was carried out by analyzing the smoothed sun glint brightness field, in [33, 34] - by iterative fitting of the satellite image brightness field and its complete physical model.

Despite the wide practice of successful application of the method in scientific research, theoretical analysis of its errors carried out in [35-37] indicates a number of significant limitations associated with nonlinear effects and inhomogeneity of constants within the considered image of the sea surface. For the purposes of this study, it is important that in works [31, 38], using photographs taken from 
the platform of the Black Sea hydrophysical sub-satellite polygon (Katsiveli), the method was applied to assess the spatial spectra of short waves at different wind speeds. Similar estimates of the spatial spectra of short waves near California [39], obtained using video recording with a polarimetric camera in the framework of a fundamentally different approach to assessing surface slopes [40], fully confirmed the conclusions [38] about the level of the short-wave spectrum and its dependence on the modulus and azimuth of the wavelength vector $\mathbf{k}$; therefore, in the present paper, the equation (1) will be applied to estimate the spectral contrasts of slicks.

In [31, 38], stereo photography data was used to calibrate the method. Stereo processing of sea surface images is possible only if there are markers on it - shortwave ripple trains. The ripple is suppressed by the film in the slick region; therefore, in the present study, the technique [31, 38] cannot be fully applied. At the same time, the MTF is determined mainly by the lighting conditions and the geometry of the observation (see, for example, [26, 35]). If they are assumed to be the same for a slick and a clean surface, then the MTF value remains unchanged. In this case, as follows from formula (1), the MTF will not be included into the expression for spectral contrast, which can be found using only the brightness spectra:

$$
K(\mathbf{k})=\left(S_{H}(\mathbf{k})\right)_{0} /\left(S_{H}(\mathbf{k})\right)_{\text {slick }}=\left(S_{B}(\mathbf{k})\right)_{0} /\left(S_{B}(\mathbf{k})\right)_{\text {slick }},
$$

where indices 0 and slick refer to a clean sea surface and a surface covered with a film, respectively.

Formula (2) permits to reconstruct spectral contrasts from photographs of the sea surface. However, as follows from formula (1), the MTF is singular in

the directions of the wave vector satisfying the condition $G_{x} k_{x}+G_{y} k_{y}=0$. For these directions, the brightness spectrum is formed by nonlinear mechanisms [31, 35]. Accordingly, the described method cannot provide spectral contrasts in the vicinity of these directions.

\section{Experiments}

The experiments were carried out from the oceanographic platform of Marine Hydrophysical Institute (Katsiveli) in 2009-2011 by forming artificial slicks using a thin film of vegetable oil. Spilling of vegetable oil from a boat or from a platform was carried out taking into account the direction of the wind and current so that a slick spot with a typical size of 20-30 m passed through the observation field of a camera located on the platform. A digital camera SONY DSC-R1 was used to make photos. The measurement series, lasting 10-15 min with a stationary camera, included several tens of photographs of the sea surface in and out of the slick (Table). Camera settings excluded automatic correction of image brightness, color and contrast. According to the known shooting parameters (height and view angle, focal length and physical dimensions of the matrix), the images were subsequently linked to the middle plane of the sea surface. The view field of the camera, located at a height of $4.3 \mathrm{~m}$, had the form of a trapezoid with typical base dimensions of 2.3 and $3.3 \mathrm{~m}$. The camera resolution was $3888 \times 2592$ pixels, which at a shooting 
height of $\sim 4 \mathrm{~m}$ and an angle to the horizon of $30^{\circ}$ corresponds to the average resolution on the sea surface of $1-2 \mathrm{~mm}$. Simultaneously, measurements of sea surface elevations were carried out using a string wave recorder located 10-15 m from the camera observation area, as well as measurements of wind speed and direction on the platform mast at a height of $21 \mathrm{~m}$. More detailed information on the method of forming slicks is given in [15, 17], on the physical properties of a thin film of vegetable oil - in [1, 17], on the used means of measuring wind and waves - in [17, 41].

The table below provides information on experimental conditions, including average wind speed $(U)$ and significant wave height $\left(H_{S}\right)$; to characterize the stability of wind conditions during the experiment, which is necessary for the correct comparison of the spectra in pure water and in slicks obtained with a time shift of 10-20 min, which the standard deviations of the wind speed $(\delta U)$ and direction $\left(\delta \varphi_{W}\right)$. are indicated for.

\section{Experimental conditions}

\begin{tabular}{c|c|c|c|c|c|c}
\hline $\begin{array}{c}\text { Experiment } \\
\text { number }\end{array}$ & Date, time & $U, \mathrm{~m} / \mathrm{s}$ & $\delta U, \mathrm{~m} / \mathrm{s}$ & $\delta \varphi_{W}, \circ$ & $H_{S}, \mathrm{~m}$ & $\begin{array}{c}\text { Number of } \\
\text { images } \\
\text { (background/ } \\
\text { slick) }\end{array}$ \\
\hline 1 & $13.10 .2009,10: 05-10: 22$ & 7.8 & 0.3 & 2.2 & 0.49 & $68 / 28$ \\
2 & $13.10 .2009,10: 24-10: 42$ & 7.9 & 0.2 & 2.5 & 0.53 & $46 / 29$ \\
3 & $24.08 .2010,15: 48-16: 24$ & 0.5 & 0.1 & 9.8 & 0.42 & $18 / 60$ \\
5 & $01.10 .2011,11: 55-12: 30$ & 7.4 & 0.5 & 38 & 0.27 & $72 / 69$ \\
\hline
\end{tabular}

Examples of fragments of images of a clean sea and a film-covered sea surface covered with a film for moderate wind speed (experiment 1) and almost calm conditions (experiment 3) are shown in Fig. 1. On a clean surface, ripples and numerous systems of capillary waves are observed, while the surface in a slick is smoother. Separate trains of capillary waves are found in many slick images in experiment 1 , but their number is much less than in images of a clean surface. At low wind speed, short waves are practically absent in the slick. The insets show enlarged fragments of images - a train of parasitic capillary waves (Fig. 1, c), confirming the presence of such waves at a low wind speed, and concentrically diverging capillary waves from a fishing line accidentally caught in the frame (Fig. 1,d), confirming that the absence of ripples in the frame is not caused by camera defocusing. 


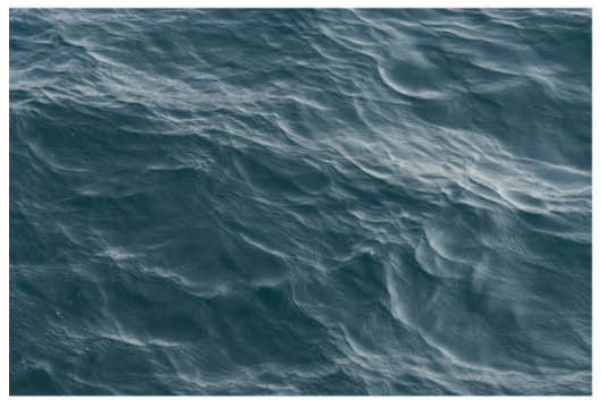

a

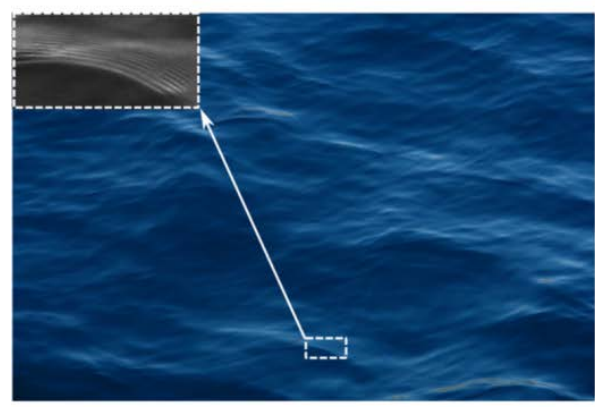

C

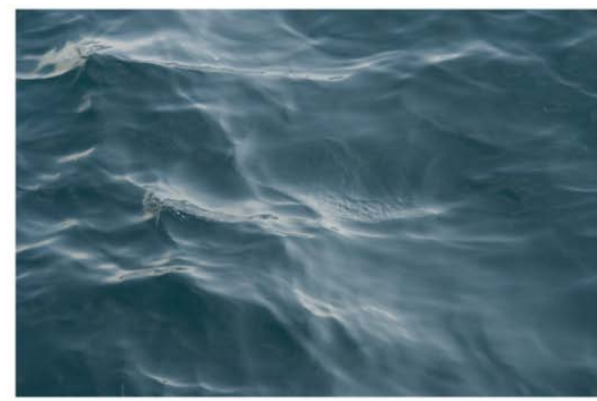

$b$

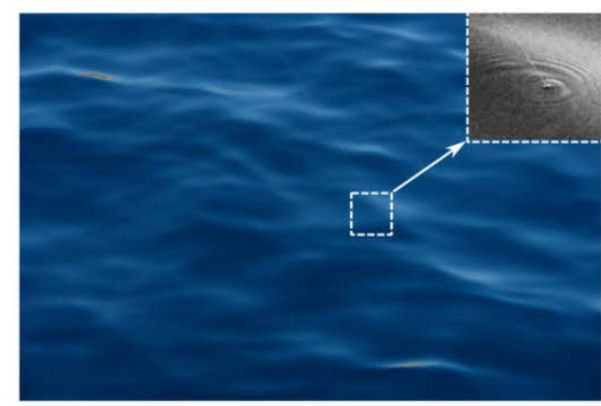

$d$

F i g. 1. Photographs of a clean sea surface $(a, c)$ and a slick-covered surface $(b, d)$ for moderate $(a$, $b$, experiment 1$)$ and low ( $c, d$, experiment 3 ) wind speeds

\section{Spectral contrasts}

The photographs of each measurement series were separated into RGB components. The images of the green channel, the least susceptible to hardware noise, since most modern cameras use a Bayer filter consisting of $25 \%$ red, $25 \%$ blue and 50\% green elements [42] will be considered below. After pixel-by-pixel binding to the coordinates on the horizontal plane at the level of the undisturbed sea surface, a two-dimensional Fourier transform was performed for the brightness fields of three partially intersecting square areas with a size of $1.5 \times 1.5 \mathrm{~m}$, overlapping the view area. The brightness spectra were estimated in a standard way: $S_{B}(\mathbf{k})=b(\mathbf{k}) b^{*}(\mathbf{k}) \quad$ (see, for example, [43]), where $b(\mathbf{k})$ are the Fourier components of the brightness; the asterisk means complex conjugation, and the averaging was carried out over these areas for all images related to a slick or to a clean surface.

Fig. 2 shows an example of two-dimensional brightness spectra obtained inside and outside the slick area. Spectra $B_{B}=k^{2} S_{B}$ are shown that give the luminance display of the Phillips saturation spectrum $B=k^{4} S_{H}(\mathbf{k})$. The spectra are plotted on the decibel scale $10 \cdot \log _{10}\left(B_{B} / B_{\max }\right)$, where $B_{\max }$ is the maximum for both spectra. When using the MTF, the saturation spectrum turns out to be 
multiplied by $\cos ^{2}\left(\varphi-\varphi_{G}\right)$, where $\varphi$ and $\varphi_{G}$ are the directions of the vectors $k$ and G (see formula (1)). As is known (see, e.g., [38]), outside the slick, the saturation spectrum level takes visually comparable values in the entire considered range of wavenumbers. This is what can be seen in Fig. 2, $a$. In slicks, the short-wavelength part of the spectrum is suppressed by the film, which is clearly shown by comparison of Fig. 2, $a, 2, b$. These figures also show the typical angular shape of the brightness spectra associated with $\cos ^{2}\left(\varphi-\varphi_{G}\right)$. The minimum brightness values are achieved at $\varphi-\varphi_{G}= \pm \pi / 2$ (shown by solid lines in Fig. 2, $a, 2, b$ ). The orientation of the picture is the same outside the slick and inside its area, which confirms the assumption that the MTF remains unchanged.
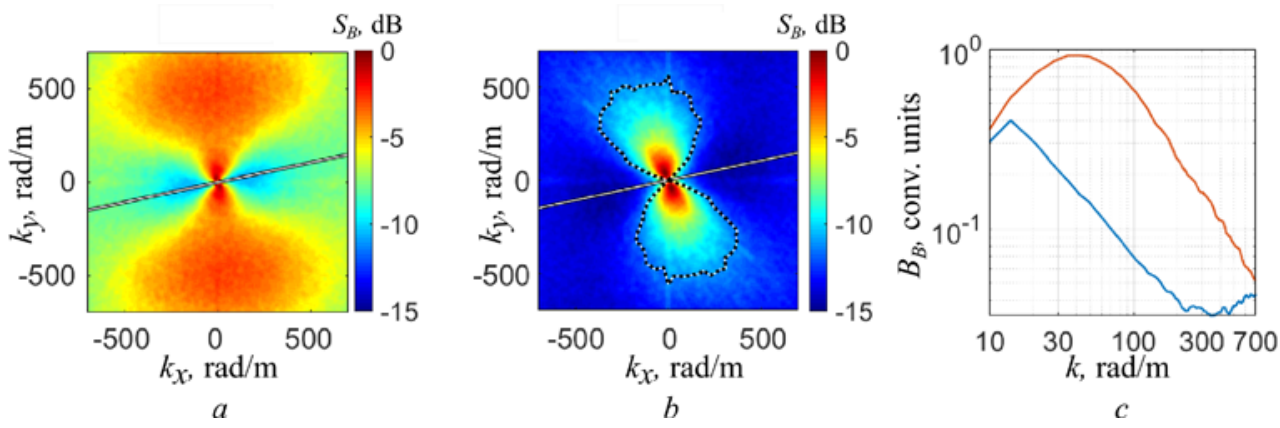

F i g. 2. Brightness saturation spectra in experiment 4: $a$ - background; $b$ - slick; $c$ - spectra $k B_{B}(k, \varphi)$ in a slick along $\varphi=\varphi_{G}+\pi / 2$ (blue) and $\varphi=\varphi_{G}$ (red) transects. Solid straight lines indicate the direction $\varphi-\varphi_{G}= \pm \pi / 2$, dotted line $(b)$ - the working area

A significant limitation of the considered approach to the assessment of contrasts is associated with the presence of noise, which, with a decrease in the spectral density of waves under slick conditions, turns out to be comparable in level with the useful signal. Sources of noise, other than the hardware ones, are spatial irregularities in illumination, wave breaking and their consequences in the form of floating bubbles, sunbeams, as well as effects associated with deviation from the linear law (formula (1)) during the surface brightness formation by wave slopes. To minimize noise, photographs were always taken in an area remote from the sun glint zone, and photographs that had fragments of whitecaps were rejected by visual inspection. To get an idea of the spectral noise level, a section of the brightness spectrum in a slick along the direction $\varphi-\varphi_{G}= \pm \pi / 2$ where, according to formula (1), there is no useful signal, is to be considered. An example of spectrum cross section $k B_{B}(k, \varphi)$ along the line shown in Fig. 2, $b$ is given in Fig. 2, $c$, which also shows the cross section of the spectrum in the perpendicular direction. As the wavenumber increases, the noise level becomes comparable to the total signal level. Therefore, further analysis will refer only to the spectral regions in the slicks, where the total signal exceeds the noise level at least twice. Hereinafter, we will refer to such areas of confidence in signals as working area. 
An example of a working area is shown in Fig. 2, $b$. Note that such an analysis for the blue and red components of the RGB image gave the working areas of a significantly smaller size than for the green component.

Fig. 3 shows the spectral contrasts (formula (2)) in the working areas for all experiments. At moderate wind speeds, the contrasts increase with the wavenumber, reaching values of $\sim 10$ at the boundaries of the working areas at $\mathrm{k} \sim 500 \mathrm{rad} / \mathrm{m}$. Under conditions close to calm (experiment 3, Fig. 3, c), the maximum contrast is localized not only in angle, but also in wavelength, and reaches values of several tens. Experiments 1 and 2 were carried out under practically the same wave conditions, but shifted in time, which led to a change in illumination conditions and a corresponding turn of the vector $\mathbf{G}$ in the MTF. As a result, the working areas in these cases complement each other, clarifying the angular dependence of the contrast. As follows from the entire set of figures, the maximum contrasts are achieved in the directions of the waves, approximately perpendicular to the direction of the wind.
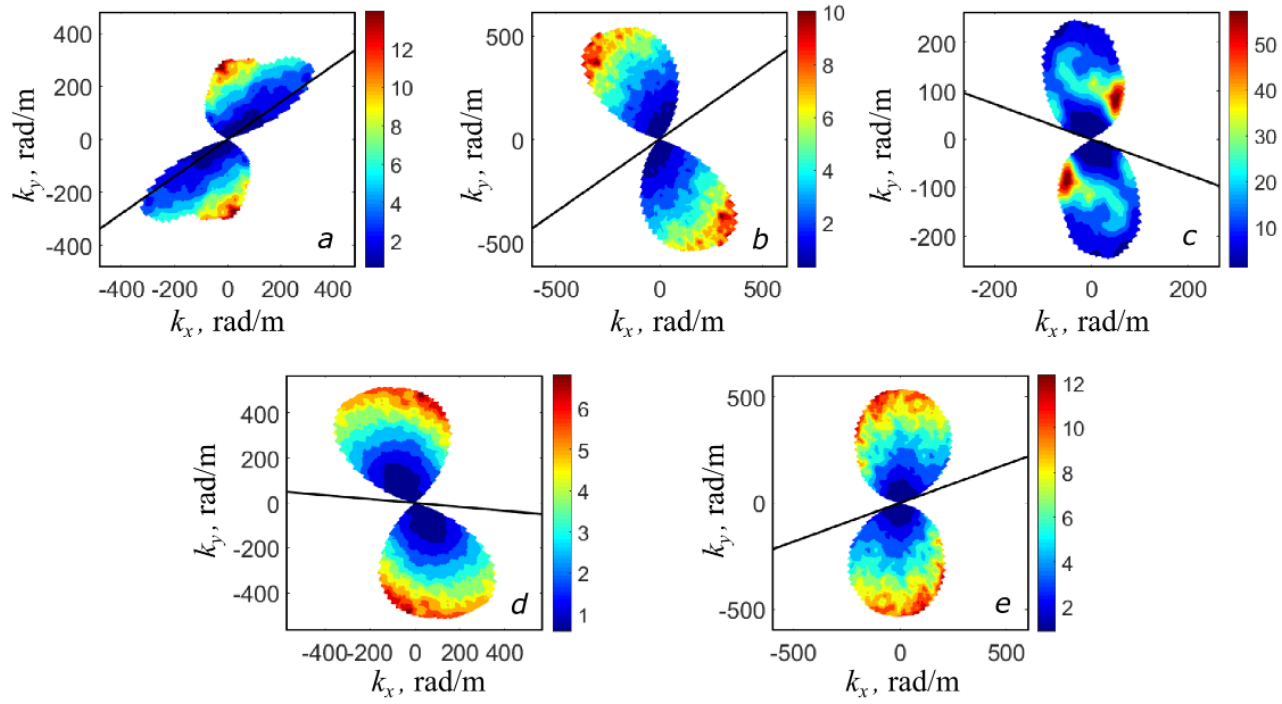

F i g. 3. Spectral contrasts in the working areas for experiments 1-5 (a-e, respectively). Lines indicate the average wind direction

\section{Discussion}

Fig. 4, a shows the dependences of the contrasts on the wavenumber at moderate wind speeds for experiments 1 and 5. The azimuth-average and maximum field contrasts determined within the working regions are shown. The figure also gives a generalized array of various data on contrasts on a vegetable oil film at wind speeds of $6-8 \mathrm{~m} / \mathrm{s}$. These data are taken from Fig. 7 and 9 in [24]. Curves for experimental series 1 and 5 are consistent with known empirical information. However, similar curves for experiments 2 and 4 (not shown in the figure) demonstrate approximately half the contrasts. A possible reason for this is the above-mentioned noise, which is added to the spectrum of brightness fluctuations caused by waves, which can lead to a significant 
overestimation of the spectrum in the slicks and, accordingly, to an underestimation of the contrast.

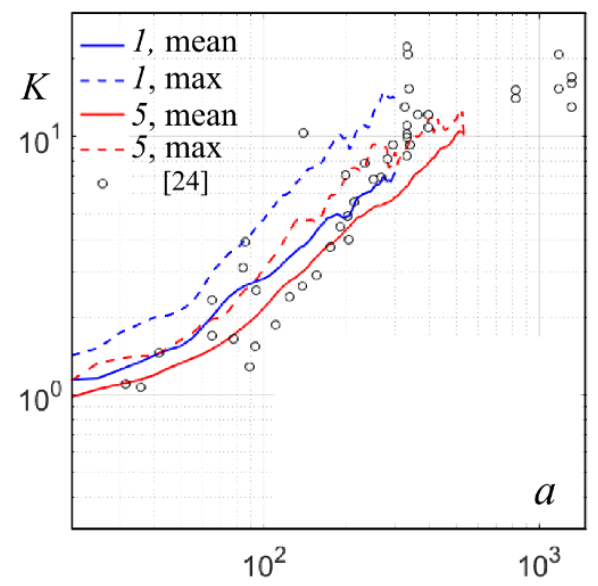

$k, \mathrm{rad} / \mathrm{m}$

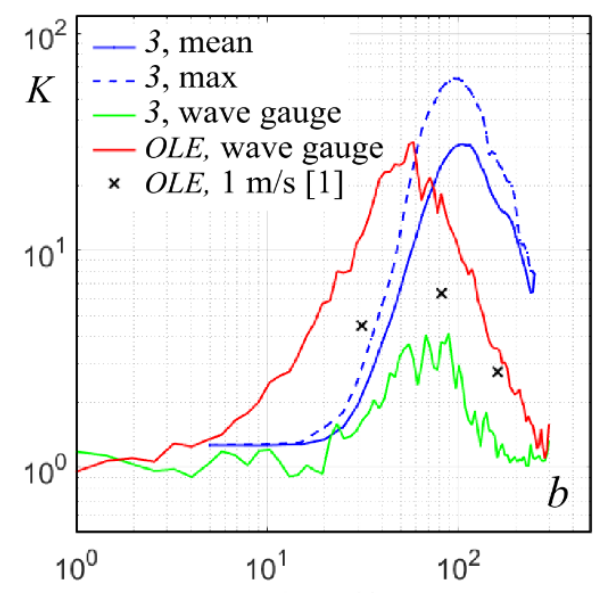

$k, \mathrm{rad} / \mathrm{m}$

F i g. 4. Dependence of the mean and maximum spectral contrasts on a wavenumber at moderate $(a)$ and low $(b)$ wind speeds in experiments $1,3,5$. Comparison with the data from the wave gauge and [1, 24]

Fig. 4, $b$ shows the dependences of the mean and maximum spectral contrasts on the wavenumber for low-wind speeds (experiment 3), demonstrating a wellpronounced peak. In [1] it is noted that a similar contrast peak was observed in a weak wind for an oleic acid film (OLE, black crosses in Fig. 4, b). In this work, a peak dependence was obtained for a vegetable oil film. Fig. $4, b$ also demonstrates the contrasts calculated from the wave gauge data, obtained during experiment 3. It was used to estimate the frequency spectra of the waves for pure water and slick. The frequency spectra conversion $S_{H}(\omega)$ into spectra by wave numbers $S_{H}(k)=S_{H}(\omega)(d \omega / d k)$ was carried out using the dispersion relation for linear gravitational-capillary waves

$$
\omega=\sqrt{g k+T k^{3} / \rho},
$$

where ${ }_{\omega}$ is the circular frequency; $g$ is the gravity; $\rho$ is the water density; $T$ is the surface tension coefficient equal to $73 \cdot 10^{-3} \mathrm{~N} / \mathrm{m}$ for pure water, $32 \cdot 10^{-3} \mathrm{~N} / \mathrm{m}-$ for used vegetable oil [17]. In Fig. 4, $b$, the spectral contrast, estimated directly from wave measurements, also demonstrates the dependence in the form of a peak. The similar peaks were repeatedly obtained by wave recorder in the field experiments with oleic acid films under almost low-wind conditions. Unfortunately, in such films, white flakes form on the surface of the water, which interferes with the assessment of contrasts using photographs. It should be noted that a stationary wave recorder, as a rule, is not used to estimate the spectra of such short waves due to possible Doppler frequency shifts in currents and in the field of orbital velocities of long waves. In addition, for the used wave recorder design, 
the noise level at frequencies over $1 \mathrm{~Hz}$, apparently, is comparable to the wave spectrum level in the slicks [41], which, as in the case of photographs, should lead to a significantly contrast underestimation. Thus, the spectral contrast obtained with the wave recorder confirms the photographic data only at a qualitative level.
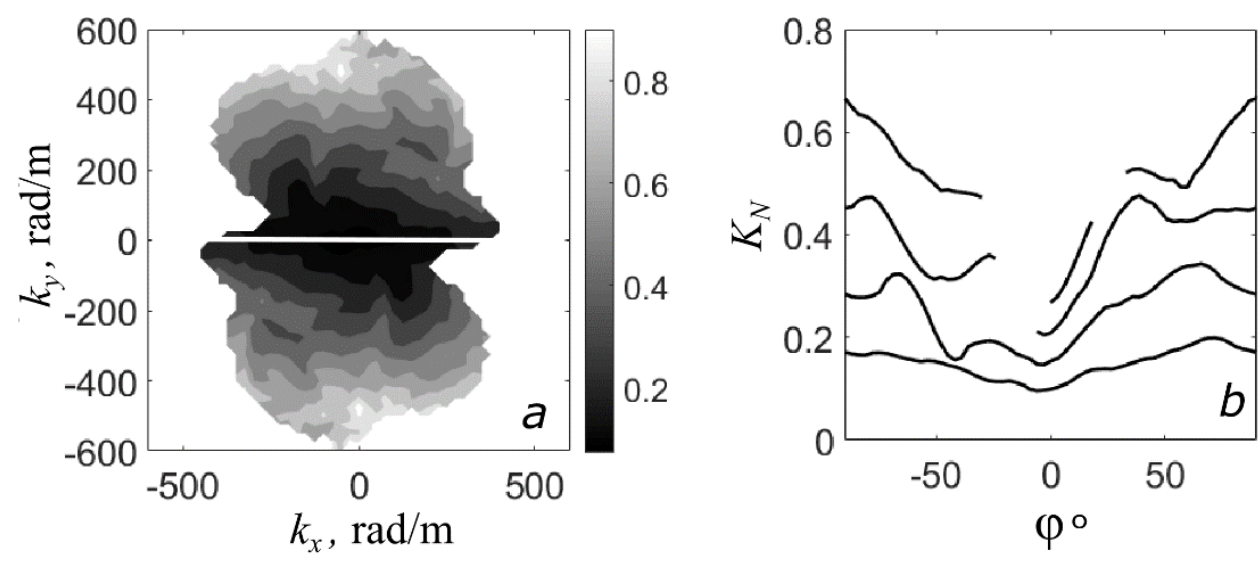

F i g. 5. Azimuthal dependence of the spectral contrasts: $a$ - field of the averaged normalized contrast $K_{N}$ (white line corresponds to the wind direction); $b$ - smoothed angular profiles $K_{N}$ for the wavenumbers (from bottom to top) 100, 200, 300 and $400 \mathrm{rad} / \mathrm{m}$

Azimuthal dependence of the spectral contrast at moderate winds, which follows from the four fields of spectral contrasts (experiments 1, 2, 4 and 5 in Fig. 3), is difficult to determine, since the working areas in each experiment do not cover all azimuths. To show this dependence clearly, the contrast fields, normalized to their maximum values, were aligned and deployed in such a way that the wind direction in each case corresponded to the azimuth $\varphi=0$. The normalized contrast $K_{N}$ at the overlapping points of the working areas was taken to be equal to the average over the overlapping data. The resulting field $K_{N}$ is shown in Fig. 5 , $a$, in $5, b$ for detailing the picture, smoothed dependences $K_{N}(\varphi)$ for fixed wavenumbers are shown. This figure presents a clear azimuthal contrast anisotropy with a minimum in the wind direction and an increase in contrast in the transverse directions. The angular difference in contrast increases with the growing wavenumber.

Noted regularities of the spectral contrasts distribution correspond to the known theoretical concepts. Growth of contrasts with an increase in the wavenumber at moderate winds is predicted by the simplest theoretical model of suppression of short waves in slicks [1,25]. Localized contrast maximum at low winds reflects the theoretical conclusions following from the Marangoni effect consideration [1]. Anisotropic distribution of contrasts can be explained by the following general considerations. The energy input from the wind to the waves is carried out mainly in the directions close to the one of wind [44]. In these directions, accordingly, the maximum values of the spectral density of short waves are observed (see, for example, [38]). Waves propagating across the wind can only 
be generated by nonlinear mechanisms of wave interaction: resonance interactions [45], generation of short waves when breaking longer waves [46], generation of parasitic ripples on the crests of short waves and possibly other effects. With a decrease in the spectrum level in a slick, the intensity of nonlinear processes decreases to a greater extent than linear wind pumping, i.e., the generation of waves in directions approximately perpendicular to the wind direction is suppressed; therefore, for such directions, the greatest spectral contrast takes place.

\section{Conclusion}

Spectral contrasts of short wind waves in artificial films of vegetable oil were estimated in field conditions using a series of photographs of the sea surface. The estimation method assumes a linear relationship between brightness fluctuations and surface slopes, which implies a conceptually simple way of obtaining contrasts using only standard spectral processing of photographs. This method implements the idea of simultaneous spectral contrasts obtained in a wide range of both module and directions of wave vectors of short waves.

Processing of photographs with vegetable oil films taken in field experiments showed that, under moderate winds, the dependence of the contrast on the wavenumber is monotonic and corresponds to the known data, while under low winds it has a resonant character with a peak at wavenumbers $\sim 100 \mathrm{rad} / \mathrm{m}$. At the same time, the contrast distribution anisotropy was revealed: the contrasts are minimal at angles close to the wind direction and grow when deviating from it. At moderate winds, the anisotropy increases with wave number.

The described method for assessing spectral contrasts can be applied in specialized hydrophysical experiments, in particular, for obtaining rapid estimates of contrasts when measured using more subtle methods. The obtained experimental results can be of interest for theoretical modeling of the short wind waves spectra and for determining the assessment of the SAS film effect on them.

\section{REFERENCES}

1. Ermakov, S.A., 2010. [Influence of the Surfactant Films on the Dynamics of GravityCapillary Waves]. Nizhny Novgorod: IAP RAS, 164 p (in Russian).

2. Ermakov, S.A., Kapustin, I.A., Lazareva, T.N., Sergievskaya, I.A. and Andriyanova, N.V., 2013. On the Possibilities of Radar Probing of Eutrophication Zones in Water Reservoirs. Izvestiya, Atmospheric and Oceanic Physics, 49(3), pp. 307-314. doi:10.1134/S0001433813030055

3. Cox, C.S., Zhang, X. and Duda, T.F., 2017. Suppressing Breakers with Polar Oil Films: Using an Epic Sea Rescue to Model Wave Energy Budgets. Geophysical Research Letters, 44(3), pp. 1414-1421. doi:10.1002/2016GL071505

4. Ermakov, S.A., Sergievskaya, I.A., Da Silva, J.C.B., Kapustin, I.A., Shomina, O.V., Kupaev, A.V. and Molkov, A.A., 2018. Remote Sensing of Organic Films on the Water Surface Using Dual Co-Polarized Ship-Based X-/C-/S-Band Radar and TerraSAR-X. Remote Sensing, 10(7), 1097. doi:10.3390/rs10071097

5. Benetazzo, A., Cavaleri, L., Ma, H., Jiang, S., Bergamasco, F., Jiang, W., Chen, S. and Qiao, F., 2019. Analysis of the Effect of Fish Oil on Wind Waves and Implications for AirWater Interaction Studies. Ocean Science, 15(3), pp. 725-743. https://doi.org/10.5194/ os-15-725-2019 
6. Bondur, V.G., 2011. Aerospace Methods and Technologies for Monitoring Oil and Gas Areas and Facilities. Izvestiya, Atmospheric and Oceanic Physics, 47(9), pp. 1007-1018. doi:10.1134/S0001433811090039

7. Kudryavtsev, V., Myasoedov, A., Chapron, B., Johannessen, J.A. and Collard, F., 2012. Joint Sun-Glitter and Radar Imagery of Surface Slicks. Remote Sensing of Environment, 120, pp. 123-132. doi:10.1016/j.rse.2011.06.029

8. Lavrova, O.Yu., Mityagina, M.I. and Kostianoy, A.G., 2016. Satellite Methods for Detecting and Monitoring Marine Zones of Ecological Risk. Moscow: SRI RAS, 334 p (in Russian).

9. Fingas, M. and Brown, C.E., 2018. A Review of Oil Spill Remote Sensing. Sensors, 18(1), 91. doi:10.3390/s18010091

10. Bondur, V.G., 2004. Aerospace Methods in Modern Oceanology. In: M. E. Vinogradov and S. S. Lappo, eds., 2004. New Ideas in Oceanology. Vol. I: Physics. Chemistry. Biology. Moscow: Nauka, pp. 55-117 (in Russian).

11. Yurovskaya, M.V., Kudryavtsev, V.N., Chapron, B. and Dulov, V.A., 2014. Interpretation of Black Sea Optical Satellite Images in Sun Glitter Area. Morskoy Gidrofizicheskiy Zhurnal, (4), pp. 68-82 (in Russian).

12. Dulov, B.A., Yurovskaya, M.V. and Kozlov, I.E., 2015. Coastal Zone of Sevastopol on High Resolution Satellite Images. Physical Oceanography, (6), pp. 39-54. doi:10.22449/1573160X-2015-6-39-54

13. Kapustin, I.A., Shomina, O.V., Ermoshkin, A.V., Bogatov, N.A., Kupaev, A.V., Molkov, A.A. and Ermakov, S.A., 2019. On Capabilities of Tracking Marine Surface Currents Using Artificial Film Slicks. Remote Sensing, 11(7), 840. doi:10.3390/rs11070840

14. Cox, C. and Munk, W., 1954. Measurement of the Roughness of the Sea Surface from Photographs of the Sun's Glitter. Journal of the Optical Society of America, 44(11), pp. 838850. https://doi.org/10.1364/JOSA.44.000838

15. Malinovsky, V.V., Dulov, V.A., Korinenko, A.E., Bol’shakov, A.N. and Smolov, V.E., 2007. Field Investigations of the Drift of Artificial Thin Films on the Sea Surface. Izvestiya, Atmospheric and Ocean Physics, 43(1), pp. 103-111. doi:10.1134/S0001433807010124

16. Munk, W., 2009. An Inconvenient Sea Truth: Spread, Steepness, and Skewness of Surface Slopes. Annual Review of Marine Science, 1, pp. 377-415. doi:10.1146/annurev.marine.010908.163940

17. Korinenko, A.E. and Malinovsky, V.V., 2014. Field Study of Film Spreading on a Sea Surface. Oceanologia, 56(3), pp. 461-475. doi:10.5697/oc.56-3.461

18. Ermakov, S.A., Pelinovsky, E.N. and Talipova, T.G., 1980. Influence of Surface-Active Material Films upon Spectral Changes in Wind Ripple Produced by Internal Waves. Izvestiya Akademii Nauk SSSR Fizika Atmosfery i Okeana, 16(10), pp. 1068-1076 (in Russian).

19. Ermakov, S.A., Salashin, S.G. and Panchenko, A.R., 1992. Film Slicks on the Sea Surface and Some Mechanisms of Their Formation. Dynamics of Atmospheres and Oceans, 16(3-4), pp. 279-304. https://doi.org/10.1016/0377-0265(92)90010-Q

20. Gade, M., Alpers, W., Hühnerfuss, H., Wismann, V.R. and Lange, P.A., 1998. On the Reduction of the Radar Backscatter by Oceanic Surface Films: Scatterometer Measurements and Their Theoretical Interpretation. Remote Sensing of Environment, 66(1), pp. 52-70. doi:10.1016/S0034-4257(98)00034-0

21. Gade, M., Alpers, W., Hühnerfuss, H., Masuko, H. and Kobayashi, T., 1998. Imaging of Biogenic and Anthropogenic Ocean Surface Films by the Multifrequency/Multipolarization SIR-C/X-SAR. Journal of Geophysical Research: Oceans, 103(C9), pp. 18851-18866. https://doi.org/10.1029/97JC01915

22. Skrunes, S., Brekke, C., Eltoft, T. and Kudryavtsev, V., 2015. Comparing Near-Coincident Cand X-Band SAR Acquisitions of Marine Oil Spills. IEEE Transactions on Geoscience and Remote Sensing, 53(4), pp. 1958-1975. doi:10.1109/TGRS.2014.2351417

23. Hansen, M.W., Kudryavtsev, V., Chapron, B., Brekke, C. and Johannessen, J.A., 2016. Wave Breaking in Slicks: Impacts on C-Band Quad-Polarized SAR Measurements. IEEE Journal of 
Selected Topics in Applied Earth Observations and Remote Sensing, 9(11), pp. 4929-4940. doi:10.1109/JSTARS.2016.2587840

24. Ermakov, S.A., Sergievskaya, I.A. and Gushchin, L.A., 2006. [Remote Sensing of Films of Marine Surface]. Sovremennye Problemy Distantsionnogo Zondirovaniya Zemli iz Kosmosa, 3(2), pp. 86-98 (in Russian).

25. Kudryavtsev, V.N., Ivanova, N.A., Gushchin, L.A. and Ermakov, S.A., 2008. [An Estimate of Wind Waves Damping by Biogenic and Oil Surface Films]. Preprint no. 765. Nizhny Novgorod: IAP RAS, 30 p. (in Russian).

26. Stilwell, D., 1969. Directional Energy Spectra of the Sea from Photographs. Journal of Geophysical Research: Oceans, 74(8), $\quad$ pp. 1974-1986. https://doi.org/10.1029/JB074i008p01974

27. Ermakov, S.A., Zujkova, A.M. and Salashin, S.G., 1987. Transformation of Short Wind Wave Spectra in Film Slicks. Izvestiya Akademii Nauk SSSR Fizika Atmosfery i Okeana, 23(7), pp. 707-715 (in Russian).

28. Bol'shakov, A.N., Burdjugov, V.M., Grodsky, S.A. and Kudrjavtsev, V.N., 1990. TwoDimensional Surface Elevation Spectra from Airphoto Data. Izvestiya Akademii Nauk SSSR Fizika Atmosfery i Okeana, 26(6), pp. 652-658 (in Russian).

29. Bol'shakov, A.N., Burdyugov, V. M., Grodskii, S.A., Kudryavtsev, V.N., and Proshchenko, V.G., 1990. Spectra of Energy-Bearing Surface Waves Determined from Sun Glitter Images. Comparison with In-Situ Data. Issledovanie Zemli iz Kosmosa, (1), pp. 20-27 (in Russian).

30. Lupyan, E.A., 1988. Reconstructing the Angular Energy Distribution in the 2D-Spectrum of the Rough Sea Surface from Its Optical Imagery. Issledovanie Zemli iz Kosmosa, (3), pp. 3135 (in Russian).

31. Kosnik, M.V. and Dulov, V.A., 2011. Extraction of Short Wind Wave Spectra from Stereo Images of the Sea Surface. Measurement Science and Technology, 22(1), 015504. doi:10.1088/0957-0233/22/1/015504

32. Kudryavtsev, V., Yurovskaya, M., Chapron, B., Collard, F. and Donlon, C., 2017. Sun Glitter Imagery of Ocean Surface Waves. Part 1: Directional Spectrum Retrieval and Validation. Journal of Geophysical Research: Oceans, 122(2), pp. 1369-1383. doi:10.1002/2016JC012425

33. Murynin, A.B., 1990. Sea Surface 2-D Spectra Recovered from Optical Images in Nonlinear Radiance Model. Issledovanie Zemli iz Kosmosa, (6), pp. 60-70 (in Russian).

34. Bondur, V.G., Dulov, V.A., Murynin, A.B. and Yurovsky, Yu.Yu., 2016. A Study of SeaWave Spectra in a Wide Wavelength Range from Satellite and In-Situ Data. Izvestiya, Atmospheric and Oceanic Physics, 52(9), pp. 888-903. doi:10.1134/S0001433816090097

35. Monaldo, F.M. and Kasevich, R.S., 1981. Daylight Imagery of Ocean Surface Waves for Wave Spectra. Journal of Physical Oceanography, 11(2), pp. 272-283. https://doi.org/10.1175/1520-0485(1981)011<0272:DIOOSW>2.0.CO;2

36. Chapman, R.D. and Irani, G.B., 1981. Errors in Estimating Slope Spectra from Wave Images. Applied Optics, 20(20), pp. 3645-3652. https://doi.org/10.1364/AO.20.003645

37. Sergievskaya, I.A., 2010. Possibilities of Using Optical Spectral Analysis to Estimate Characteristics of Roughness in the Presence of Films on the Sea Surface. Izvestiya, Atmospheric and Oceanic Physics, 46(1), pp. 121-127. https://doi.org/10.1134/S0001433810010159

38. Yurovskaya, M.V., Dulov, V.A., Chapron, B. and Kudryavtsev, V.N., 2013. Directional Short Wind Wave Spectra Derived from the Sea Surface Photography. Journal of Geophysical Research: Oceans, 118(9), pp. 4380-4394. doi:10.1002/jgrc.20296

39. Laxague, N.J.M., Zappa, C.J., LeBel, D.A. and Banner, M.L., 2018. Spectral Characteristics of Gravity-Capillary Waves, with Connections to Wave Growth and Microbreaking. Journal of Geophysical Research: Oceans, 123(7), pp. 4576-4592. https://doi.org/10.1029/2018JC013859 
40. Zappa, C.J., Banner, M.L., Schultz, H., Corrada-Emmanuel, A., Wolff, L.B. and Yalcin, J., 2008. Retrieval of Short Ocean Wave Slope Using Polarimetric Imaging. Measurement Science and Technology, 19(5), 055503. https://doi.org/10.1088/0957-0233/19/5/055503

41. Yurovsky, Yu.Yu. and Dulov, V.A., 2020. MEMS-Based Wave Buoy: Towards Short Wind$\begin{array}{lllll}\text { Wave Sensing. } & \text { Ocean } & \text { Engineering, }\end{array}$ https://doi.org/10.1016/j.oceaneng.2020.108043

42. Jähne, B., 2005. Digital Image Processing. Berlin: Springer, 608 p. doi:10.1007/3-54027563-0

43. Bendat, J.S. and Piersol, A.G., 2010. Random Data: Analysis and Measurement Procedures. New York: Wiley, 640 p.

44. Plant, W.J., 1982. A Relation between Wind Stress and Wave Slope. Journal of Geophysical Research: Oceans, 87(C3), pp. 1961-1967. https://doi.org/10.1029/JC087iC03p01961

45. Dulov, V.A. and Kosnik, M.V., 2009. Effects of Three-Wave Interactions in the GravityCapillary Range of Wind Waves. Izvestiya, Atmospheric and Oceanic Physics, 45(3), pp. 380391. doi:10.1134/S0001433809030116

46. Kudryavtsev, V. and Johannessen, J., 2004. On Effect of Wave Breaking on Short Wind Waves. Geophysical Research Letters, 31(20), L20310. doi:10.1029/2004GL020619

About the authors:

Vladimir A. Dulov, Head of the Laboratory of Applied Sea Physics of the Department of Remote Research Methods, Marine Hydrophysical Institute of RAS (2 Kapitanskaya str., Sevastopol, 299011, Russian Federation), Dr.Sci. (Maths.-Phys.), ORCID ID: 0000-0002-0038-7255, ResearcherID: F-8868-2014, dulov1952@gmail.com

Marya V. Yurovskaya, Senior Research Associate, Marine Hydrophysical Institute of RAS (2 Kapitanskaya str., Sevastopol, 299011, Russian Federation), Ph.D. (Maths.-Phys.); Research Associate of Satellite Oceanography Laboratory, Russian State Hydrometeorological University (79 Voronezhskaya St., Saint Petersburg, 192007, Russian Federation), ORCID ID: 0000-00016607-4641, ResearcherID: F-8957-2014, mvkosnik@gmail.com

Contribution of the co-authors:

Vladimir A. Dulov - analysis of materials and literature on the methods and subject of research; formulation of the goals and objectives of the study; participation in the method development; analysis and generalization of work results; preparation of the article text

Marya V. Yurovskaya - data collection during field experiments in 2009-2011; participation in the method development; computer implementation of algorithms; discussion of research results; editing and supplementing the text of the article

All the authors have read and approved the final manuscript.

The authors declare that they have no conflict of interest. 